\title{
Una teoría económica del control judicial de la discrecionalidad Administrativa
}

\author{
Gabriel Doménech Pascual \\ Catedrático de Derecho Administrativo \\ Universidad de Valencia
}

SUMARIO: I. INTRODUGGIÓN. II. DOS GUESTIONES PREVIAS. 1. El deber de tomar la mejor decisión posible para el interés público. 2. El concepto de discrecionalidad. La discutible teoría de los conceptos jurídicos indeterminados. III. JUSTIFICACIÓN DE LA DISGRECIONALIDAD ADMINISTRATIVA. 1. Costes de la discrecionalidad administrativa. A) Reducción de los beneficios del control judicial de la actividad de las Administraciones públicas. a) Corrección de ilegalidades. b) Prevención de ilegalidades. B) Incremento del riesgo de decisiones desviadas. 2. Beneficios de la discrecionalidad administrativa. A) Reducción de los costes del control judicial. a) Costes de procedimiento. b) Costes de los errores judiciales. B) La discrecionalidad administrativa como instrumento de minimización del riesgo de errores. G) La discrecionalidad administrativa como instrumento de legitimación. IV. EL ALCANGE ÓPTIMO DE LA DISGREGIONALIDAD ADMINISTRATIVA Y, POR ENDE, DE SU CONTROL JUDICIAL. 1. Factores determinantes. 2. El factor estratégico. 3. Poderes del juez frente a las decisiones administrativas ilegales. V. UNA TEORÍA SUSTANGIALMENTE ACORDE CON LAJURISPRUDENCIA. BIBLIOGRAFÍA.

RESUMEN: El presente trabajo esboza, desde la perspectiva del análisis económico del Derecho, una teoría general acerca del control judicial de la discrecionalidad administrativa que permita responder a tres cuestiones fundamentales: por qué, en determinadas circunstancias, los Tribunales deben reconocer un margen de discrecionalidad a las Administraciones públicas cuando revisan las decisiones de éstas; en qué circunstancias deben reconocerlo; y cuáles son los límites que lo definen. A estos efectos, el trabajo analiza los costes y beneficios sociales de esa discrecionalidad, y señala algunas variables de los que ambos dependen y que, por consiguiente, permiten determinar en cada caso hasta qué punto la misma está justificada.

PALABRAS CLAVE: justicia administrativa; control judicial; discrecionalidad administrativa; análisis económico del Derecho. 
ABSTRACT: This paper presents, from a law and economics perspective, a general theory on judicial review of administrative discretion. This theory allows answering at least three questions: (i) What is the rationale of administrative discretion? (ii) Under which circumstances should administrative authorities enjoy it? and (iii) Which is the optimal scope of that discretion? With that purpose, the paper analyzes the social costs and benefits of administrative discretion, which determine whether and to what extent it is justified in each case.

KEY WORDS: judicial review; administrative discretion; law and economics.

\section{INTRODUGGIÓN}

Seguramente no exista en el ámbito del Derecho administrativo un problema que tenga una superior relevancia práctica, sobre el que se haya escrito una mayor cantidad de páginas y que haya dado lugar a discusiones doctrinales más encendidas que éste. El control judicial de la discrecionalidad administrativa es «el gran tema» ${ }^{1}$ para todos los que nos dedicamos a aplicar o estudiar esta rama del ordenamiento jurídico. Un tema que inexorablemente nos sale al paso una y otra vez, especialmente en los casos trascendentes, difíciles y controvertidos, que carecen de una solución evidente.

Es probable que las controversias suscitadas obedezcan en gran medida a que se trata de un problema ineluctablemente difícil, que no se deja resolver con reglas claras y sencillas, cuyas condiciones de aplicación pueden ser definidas de manera precisa e inequívoca. Pero, en nuestra opinión, también ha influido el hecho de que las construcciones doctrinales que hace décadas se elaboraron sobre el particular y que todavía hoy ocupan una posición dominante en el seno de la comunidad jurídica española presentan notables insuficiencias, especialmente a la hora de responder a tres cuestiones clave: (i) porqué, en determinadas circunstancias, los Tribunales deben reconocer cierto margen de apreciación o discrecionalidad a las Administraciones públicas a la hora de revisar la legalidad de las actuaciones de éstas; (ii) en qué casos deben reconocerlo; y (iii) cuáles son los límites del mismo y, por lo tanto, cuándo puede afirmarse que la Administración los ha rebasado o, por el contrario, se ha mantenido dentro de ellos.

En el presente trabajo se intenta ofrecer una respuesta a estas cuestiones y a otras conexas desde una perspectiva económica, esto es, a la vista de las consecuencias que pueden derivarse de cada una de las posibles soluciones y, en particular, de los costes y beneficios que para la sociedad cabe esperar de ellas. Interesa resaltar que el enfoque aquí adoptado es primariamente prescriptivo. Nuestra preocupación principal

FERNÁNDEZ RODRÍGUEZ, T.R. (2012, p. 144). 
es determinar cómo deberían actuar los jueces frente al fenómeno de la discrecionalidad administrativa. No tratamos de averiguar, pues, cómo actúan realmente aquí, sin perjuicio de que hagamos algunas observaciones al respecto.

\section{DOS GUESTIONES PREVIAS}

\section{El deber de tomar la mejor decisión posible para el interés público}

En España, la teoría de la discrecionalidad administrativa se ha elaborado desde la perspectiva del control judicial. Ello ha propiciado que se haya producido una identificación entre las normas jurídicas que la Administración ha de observar en el ejercicio de sus potestades discrecionales y las normas cuyo cumplimiento por parte de ésta los Tribunales han de verificar al revisar dicho ejercicio ${ }^{2}$. El control judicial llega hasta donde alcanza el Derecho, que termina donde comienza la discrecionalidad administrativa, el espacio decisorio en el que los jueces no pueden inmiscuirse porque no hay criterio jurídico alguno que permita seleccionar entre las alternativas allí existentes.

La consecuencia natural es que, siempre que se mantenga dentro de ese espacio delimitado externamente por el Derecho, la Administración puede adoptar cualquier decisión. En palabras de GARCÍA DE ENTERRÍA Y FERNÁNDEZ RODRÍGUEZ, seguramente los más destacados artífices de esa concepción teórica, «el ejercicio de una potestad discrecional permite... optar entre alternativas que son igualmente justas desde la perspectiva del Derecho»; «la discrecionalidad es esencialmente una libertad de elección... entre indiferentes jurídicos, porque la decisión se fundamenta normalmente en criterios extrajurídicos (de oportunidad, económicos, etc.), no incluidos en la ley y remitidos al juicio subjetivo de la Administración»; «el juez no puede fiscalizar la entraña de la decisión discrecional, puesto que, sea ésta del sentido que sea, si se ha producido dentro de los límites de la remisión legal a la apreciación administrativa... es necesariamente justa» ${ }^{3}$.

Esta concepción ha sido cuestionada por varios autores, que sostienen que el espacio de discrecionalidad otorgado a la Administración no constituye un indiferente jurídico. En primer lugar, porque, como bien señala Rodríguez dE SANTiago, también en ese espacio la Administración ha de observar algunas normas jurídicas,

\footnotetext{
En sentido similar, así lo advierte también PONCE SOLÉ, J. (2016, ap. 1).

GARCÍA DE ENTERRÍA, E. y FERNÁNDEZ RODRÍGUEZ, T.R. (2017). Vid., también, PAREJO ALFONSO, L. (1993, p. 60, nota 20).
} 
aunque su cumplimiento no sea perfectamente controlable por los Tribunales ${ }^{4}$. Estima este autor que, en relación con las decisiones discrecionales, hay una «asimetría» entre las normas de conducta y las normas de control ${ }^{5}$. Estas últimas constituyen los criterios con los que hay que revisar, en vía administrativa o judicial, una decisión administrativa. Las normas de conducta serían las que ha de aplicar la Administración cuando actúa. Pues bien, en los casos de discrecionalidad, la Administración completa las normas de conducta establecidas por el legislador con normas o criterios adicionales «encontrados o decididos por ella misma». Estos criterios adicionales de conducta «construidos» por la Administración sólo serían susceptibles de un control judicial «negativo»: los Tribunales sólo podrían verificar si han sido explicitados y no son inaceptables ${ }^{6}$.

En segundo lugar, y en estrecha relación con lo que acaba de decirse, las autoridades administrativas, en los márgenes de actuación que les deja el ordenamiento jurídico, deben observar siempre una norma fundamental de carácter final: la de intentar tomar la mejor decisión posible para los intereses generales ${ }^{7}$.

Nuestra posición es básicamente coincidente con la de estos autores. En los espacios de discrecionalidad, las autoridades administrativas deben observar esta norma fundamental, lo que no es óbice para que los Tribunales deban dar por válidas las decisiones que se mantengan dentro de tales espacios.

Ese deber de adoptar la mejor decisión posible para los intereses generales puede inferirse de varios preceptos de la Constitución. En primer lugar, de los principios de eficiencia y economía consagrados en su artículo 31.2. No basta que la Administración actúe al servicio de los intereses generales, sino que ha de hacerlo eficientemente, maximizando la utilidad social de sus escasos recursos. Una decisión administrativa no puede considerarse eficiente si hay otra alternativa mejor para tales intereses, bien porque ésta mejora la satisfacción de al menos alguno de ellos sin perjudicar ninguno (en la jerga de los economistas, es eficiente en el sentido de Pareto), bien porque dicha

En sentido similar, ARROYO JIMÉNEZ, L. (2009, pp. 27 y 28); y PONCE SOLÉ, J. (2016, ap. 1), quien señala que «el Derecho administrativo es algo más amplio y diferente que el mero control judicial de las decisiones administrativas».

5 Sobre esta distinción, de origen alemán, vid. RODRÍGUEZ DE SANTIAGO, J. M. (2016, pp. 24 y ss. y 165 y ss.). BACIGALUPO, M. (1997, pp. 61 y ss.) también la utiliza, si bien considera de dudosa compatibilidad con el art. 106.1 CE que el legislador establezca normas de conducta dirigidas a la Administración y, al mismo tiempo, excluya que puedan ser aplicadas, como normas de control, por los Tribunales (pp. 77 y 78). En su opinión, «las normas de conducta, dirigidas a la Administración, son siempre a la vez normas de control, dirigidas al juez» (p. 82).

6 RODRÍGUEZ DE SANTIAGO, J. M. (2016, pp. 172 y ss.).

En sentido similar, FERNÁNDEZ FARRERES, G. (1983, pp. 615 y ss.); ALONSO MAS, Ma J. (1998, pp. 361 y ss.); PONCE SOLÉ, J. (2016, ap. 3); RODRÍGUEZ DE SANTIAGO, J. M. (2016, pp. 172 y ss.). 
alternativa consigue elevar la satisfacción de algunos intereses públicos en la medida suficiente como para compensar el menoscabo que la misma supone para otros (es, por lo tanto, eficiente en sentido KALDOR-Hicks ${ }^{8}$ ).

El principio de interdicción de la arbitrariedad de los poderes públicos (art. 9.3 CE) también podría dar fundamento, al menos en algún caso, al referido deber. Resultaría injustificable racionalmente y, por ende, arbitrario, por ejemplo, el que la Administración escogiera una de las alternativas comprendidas dentro de su margen de actuación discrecional a pesar de estimar que hay otras soluciones, también situadas dentro de éste, que sirven mejor los intereses generales.

En tercer lugar, si - de acuerdo con la opinión de numerosos autores- los principios jurídicos que la Constitución consagra constituyen mandatos de optimización, que ordenan a los poderes públicos la realización de ciertos valores en la mayor medida de lo posible, habida cuenta de las limitaciones fácticas y jurídica existentes ${ }^{9}$, entonces la Administración pública está obligada a tomar la decisión que maximiza, que mejor satisface, efectivamente tales principios.

Finalmente, hay una importante razón pragmática para afirmar la existencia de un deber tal. En vista de que su observancia no puede ser verificada por los Tribunales - $\mathrm{O}$, en su caso, por el órgano administrativo encargado de revisar la decisión adoptada-y, por lo tanto, de que a su incumplimiento no va asociada sanción jurídica alguna, acaso pudiera pensarse que éste es un deber inútil, carente de cualquier efecto práctico ${ }^{10}$. Sin embargo, es razonable pensar lo contrario. Varios estudios empíricos han evidenciado que el mero hecho de que mediante una norma jurídica, dictada a través de los cauces normales de creación del Derecho, se establezca el deber de observar cierta conducta determina que muchas personas la lleven a cabo efectivamente, aun cuando su inobservancia no sea sancionable o ni siquiera fiscalizable por las autoridades ${ }^{11}$. Se han apuntado básicamente dos causas de este fenómeno. La gente, en primer lugar, respeta a veces estas normas jurídicas por presiones sociales externas. Es posible que sus destinatarios estimen que éstas reflejan el contenido de reglas, usos y preferencias sociales. Y que las cumplan por la natural tendencia de los individuos a imitar lo que hacen otros o porque perciben una cierta probabilidad de

\footnotetext{
Vid. KALDOR, N. (1939) y HICKS, J. (1939).

Vid., entre otros, ALEXY, R. (1994, pp. 75 y 76); LOPERA MESA, G.P. (2004).

10 Y ello al margen de si resulta acertado o desacertado calificar como jurídico un deber cuya infracción no puede ser controlada ni, en consecuencia, sancionada por un órgano estatal. Según KELSEN, H. (1995, p. 63), «sólo puede considerarse una conducta como jurídicamente obligatoria... cuando el comportamiento contrario está normado como condición de un acto coactivo dirigido contra el hombre que así actúa».

11 Vid., entre otros, FISMAN, R. y MIGUEL, E. (2007); GALBIATI, R. y VERTOVA, P. (2014); FRIEDMAN, L. (2016).
} 
que otras personas adviertan las infracciones y desencadenen la imposición de «sanciones sociales» -v. gr., reputacionales-, que pueden tener respecto de los potenciales infractores un efecto disuasorio incluso mayor que el de las jurídicas. En segundo término, muchas personas muestran una preferencia intrínseca por respetar el Derecho o por hacer lo que ellos consideran moralmente correcto, preferencia que en no pocos casos es lo suficientemente intensa como para que una norma jurídica sea observada aun en ausencia de cualquier sanción externa ${ }^{12}$. Nótese que el Derecho vigente a menudo influye sobre la conducta de sus destinatarios en la medida en que éstos pueden inferir de aquél información acerca de (i) cuáles son las reglas cuya infracción puede dar lugar a sanciones sociales, y (ii) la conveniencia o la corrección moral de ciertos comportamientos.

Así las cosas, cabe pensar que, si se establece el deber de las Administraciones públicas de adoptar siempre la mejor decisión posible para los intereses generales, se elevará la probabilidad de que aquéllas lo intenten efectivamente, lo cual - es de suponer- aumentará a su vez la probabilidad de que acaben consiguiéndolo o, al menos, quedándose más cerca de dicho objetivo.

\section{El concepto de discrecionalidad. La discutible teoría de los conceptos jurídicos indeterminados}

El que la Administración disponga de discrecionalidad o, si se prefiere decir así, de un margen de apreciación para decidir significa que la decisión que adopte ha de considerarse conforme a Derecho por los órganos encargados de revisarla, siempre que se mantenga dentro de unos límites, que definen ese margen o espacio en el que caben varias soluciones.

De acuerdo con la mentada teoría, importada de Alemania en los años 1960 y $1970^{13}$, las potestades discrecionales no han de ser confundidas con las potestades regladas mediante «conceptos jurídicos indeterminados». «Los conceptos utilizados por las leyes pueden ser determinados o indeterminados». Los primeros «delimitan el ámbito de realidad a que se refieren de una manera precisa e inequívoca». Los segundos aluden a «una esfera de realidad cuyos límites no aparecen bien precisados» en el enunciado de la ley, pero que «admite ser precisada en el momento de la aplicación» de la norma legal. Entonces sólo hay una solución: o se da o no se da en la realidad el concepto; «la indeterminación del enunciado no se traduce en una indeterminación de las aplicaciones del mismo, las cuales sólo permiten una "unidad de

12 Vid. COOTER, R. (2006); TYLER, T.R. (2006, p. 46); SHAVELL, S. (2012, pp. 33 у 34 ).

13 Las obras clave de esta recepción fueron las de GARCÍA DE ENTERRÍA, E. (1962, pp. 171 y ss.), GARCÍA DE ENTERRÍA, E. y FERNÁNDEZ RODRÍGUEZ, T.R. (1 ${ }^{\text {a }}$ edición de 1974) y SAINZ MORENO, F. (1976). 
solución justa" en cada caso, a la que se llega mediante una actividad de cognición, objetivable por tanto».

La consecuencia práctica es que el juez podría fiscalizar la aplicación de estos conceptos y «verificar si la solución a que con ella se ha llegado es la única solución justa que la ley permite», a diferencia de lo que sucede cuando nos encontramos con una decisión realmente discrecional, en cuya «entraña» hay un espacio de libre elección que no es fiscalizable judicialmente.

La distinción, sin embargo, se hace con algunos matices. El más relevante consiste en estimar que la Administración goza de un cierto «margen de apreciación» a la hora de interpretar y aplicar estos conceptos. Se dice, en efecto, que en la estructura de todo concepto indeterminado son identificables: un núcleo fijo o «zona de certeza positiva», referida a las realidades claramente comprendidas por el concepto; una «zona de certeza negativa», referida a las realidades excluidas con seguridad del concepto; y una zona intermedia o de incertidumbre o «halo del concepto», donde no estaría claro ni lo uno ni lo otro. Pues bien, habida cuenta de «la dificultad de acercarse de forma totalmente exacta a la solución justa», habría que reconocer que la Administración, en los casos que caen dentro de ese halo, en particular cuando se trata de conceptos que implican «juicios de valor», dispone de un cierto margen de apreciación, de una suerte de «beneficio de la duda», si bien sólo «puramente cognoscitivo e interpretativo de la ley en su aplicación a los hechos». Aquí, «el juez deberá normalmente conformarse con un control de los límites o de los excesos en que la Administración haya podido incurrir» ${ }^{14}$.

Esta distinción entre potestades discrecionales y potestades regladas mediante conceptos jurídicos indeterminados es cuestionable ${ }^{15}$. Por de pronto, no resulta coherente afirmar que los jueces pueden fiscalizar plenamente la aplicación administrati-

14 GARCÍA DE ENTERRÍA, E. y FERNÁNDEZ RODRÍGUEZ, T.R.(2017).

15 Se han mostrado críticos con la referida distinción: MARTÍN GONZÁLEZ, M., (1967, pp. 252 y ss.); PÉREZ OLEA, M. (1972, pp. 53 y ss.); SÁNCHEZ MORÓN, M. (1994, pp. 116 y ss.); BACIGALUPO, M. (1997, pp. 157 y ss.); CIRIANO VELA, C.D. (2000, pp. 126 y ss. y 442 y ss.); MUÑOZ MACHADO, S. (2015, pp. 246 y ss.); BETANCOR RODRÍGUEZ, A. (2015, pp. 117 y 118); RODRÍGUEZ DE SANTIAGO, J. M. (2016, pp. 173 y 174). Otros autores siguen admitiéndola, pero la relativizan, al estimar que en la aplicación de los conceptos jurídicos indeterminados hay discrecionalidad, siquiera instrumental o débil, y, por lo tanto, no una única solución justa (DESDENTADO DAROCA, E., 1999, pp. 101 y ss.), que «el margen de apreciación... relativiza la frontera entre lo discrecional y lo no discrecional» (BELTRÁN DE FELIPE, M., 1995, p. 42), que, «en la práctica, el margen de apreciación o valoración que implican los conceptos jurídicos indeterminados comporta también un margen de decisión (discrecionalidad), al menos en las zonas de incertidumbre» (LAGUNA DE PAZ, J.G., 2017), o que «el proceso cognoscitivo de integración de ciertos conceptos indeterminados se convierte, de facto, en una elección administrativa entre las diversas posibilidades lógicas y materiales de concretarlo sobre la realidad práctica» (MOZO SEOANE, A., 2018, p. 25). 
va de los conceptos jurídicos indeterminados y «verificar si la solución a que con ella se ha llegado es la única solución justa que la ley permite», al tiempo que se estima que los jueces han de reconocer a la Administración un «margen de apreciación» en la aplicación de los mismos.

Debe notarse, en segundo lugar, que de la referida distinción no se siguen consecuencias prácticas cualitativamente diferentes. Los jueces deben actuar y de hecho actúan de la misma manera frente a los márgenes de discrecionalidad y los de apreciación que implican tales conceptos: en los dos escenarios han de dar por válidas las decisiones y apreciaciones administrativas que no exceden ciertos límites.

En tercer lugar, la tesis de que ambos márgenes difieren en cuanto a su naturaleza - volitiva en el caso de la discrecionalidad, cognitiva en el de los conceptos jurídicos indeterminados- es también discutible. Si, como hemos visto, la Administración debe adoptar siempre la decisión más conveniente para el interés público, entonces nunca tiene libertad para optar y, por lo tanto, tanto los márgenes de discrecionalidad como los de apreciación tienen una índole cognitiva: ante la dificultad de verificar con certeza cuál es esa solución óptima, los Tribunales deben considerar válidas las decisiones administrativas que se mantengan dentro de un espacio, principalmente en atención a que las Administraciones públicas, en determinadas circunstancias, están mejor situadas que ellos para decidir acertadamente.

En cuarto lugar, esta teoría tampoco ofrece criterios que nos permitan discernir cuándo nos encontramos ante una potestad discrecional y cuándo ante una potestad reglada mediante tales conceptos.

Por último, la distinción conduce a veces a resultados paradójicos, contrarios al espíritu con el que fue formulada, que no era otro que el de intensificar el control judicial de ciertas decisiones administrativas en un determinado momento histórico. En efecto, hay disposiciones legales que obligan a la Administración a observar reglas -v. gr. de procedimiento o forma- especialmente estrictas para adoptar decisiones discrecionales, a fin de conjurar el peligro que encierra el margen de maniobra que éstas implican. El artículo 35.1.i) de la Ley 39/2015, por ejemplo, dispone que serán motivados «los actos que se dicten en el ejercicio de potestades discrecionales». Pues bien, considerar que las potestades regladas mediante conceptos jurídicos indeterminados para cuya aplicación la Administración dispone de un margen de apreciación no son discrecionales conduce, en principio, a excluirlas del ámbito de aplicación de estas reglas, a pesar de que este margen es prácticamente igual de peligroso que uno de discrecionalidad. Esta interpretación, que en algún caso ha sostenido nuestro Tribunal Supremo ${ }^{16}$, es

$16 \quad$ Vid. la STS de 12 de diciembre de 2000 (rec. 233/1999). 
ciertamente desafortunada $^{17}$, pero del todo coherente con la referida distinción, cuya artificiosidad pone de manifiesto. Ambos márgenes son sustancialmente iguales y deben recibir por ello un trato equiparable, «para lo bueno y para lo malo».

\section{JUSTIFICACIÓN DE LA DISGRECIONALIDAD ADMINISTRATIVA}

Los jueces, como cualesquiera agentes públicos, deberían adoptar las decisiones que mejor satisfagan los intereses generales, en el marco de la Constitución y del resto del ordenamiento jurídico. Lo que se ha dicho antes respecto de la Administración vale también para ellos. Y en el mismo sentido deberían decidir al juzgar si la Administración goza o no de un margen de maniobra para actuar, cuál es en su caso la anchura de éste y si la actuación considerada se ha mantenido o no dentro de sus límites.

Desde el punto de vista de la racionalidad económica, el criterio determinante para precisar, siquiera de manera aproximada y tentativa, si y, en su caso, en qué medida hay que reconocer a la Administración un espacio de discrecionalidad para actuar es el de los costes y beneficios sociales que del mismo se derivan. La discrecionalidad tiene ventajas y desventajas para la óptima satisfacción del interés público. Dicho espacio sólo estará justificado si sus beneficios excedan de sus costes para la sociedad. Y sólo estará justificado hasta el punto en el que ese balance beneficio-coste sea positivo ${ }^{18}$.

\section{Costes de la discrecionalidad administrativa}

A) Reducción de los beneficios del control judicial de la actividad de las administraciones públicas

Dar discrecionalidad a la Administración para tomar determinadas decisiones supone limitar en cierto modo el control que los Tribunales pueden ejercer sobre ellas y, por lo tanto, renunciar a algunos de los beneficios que cabría esperar de un control judicial «agotador» de las mismas, que son básicamente de dos tipos.

\section{a) Corrección de ilegalidades}

De las actuaciones administrativas contrarias al ordenamiento jurídico suelen derivarse consecuencias actual o potencialmente perjudiciales para el bienestar del conjunto de los ciudadanos. Estas infracciones pueden causar daños o poner a determinadas personas en intolerable peligro de sufrirlos.

\footnotetext{
LORA, A. (2001).

Vid. las críticas de BACIGALUPO, M. (2001) y BOCANEGRA SIERRA, R. y HUERGO

18 En sentido similar, vid. VERMEULE, A. (2016, pp. 7, 21, 60 y ss., 114 y ss., y 209 y ss.).
} 
Una de las funciones más importantes del control judicial es neutralizar o mitigar, en la medida de lo fáctica y jurídicamente posible, las consecuencias negativas antijurídicas directamente derivadas de las actuaciones administrativas enjuiciadas. Los Tribunales pueden adoptar diversas medidas con este objeto: (i) anular las disposiciones o los actos administrativos impugnados; (ii) condenar a la Administración a realizar una actuación debida, que había omitido ilegalmente; (iii) reconocer una situación jurídica menoscabada o puesta en peligro por la actuación ilegal recurrida; (iv) disponer medidas de restauración y preservación del orden jurídico conculcado por la Administración; y (v) condenarla a compensar los daños causados a los actores.

\section{b) Prevención de ilegalidades}

El control judicial cumple también una importante función preventiva de las ilegalidades que puedan cometer las Administraciones públicas. Esta función descansa sobre dos pilares: la disuasión y la información.

De un lado, el hecho que exista la posibilidad de que los Tribunales revisen las actuaciones administrativas y, en el caso de que éstas sean ilegales, adopten una o varias de las medidas mencionadas en el epígrafe anterior puede disuadir a dichas Administraciones de violar el Derecho. La potencia y el alcance del efecto disuasorio dependerán de varios factores, cuando menos de los siguientes:

En primer lugar, del coste que para la autoridad administrativa en cuestión tengan las medidas adoptadas por los Tribunales en el caso de que éstos consideren que la actividad enjuiciada es ilegal. Cuanto más costosas sean, más intenso será dicho efecto.

El segundo factor relevante es la probabilidad de que la actuación administrativa ilegal considerada sea impugnada y declarada contraria a Derecho por los Tribunales. Cuanto más elevada sea esa probabilidad, mayor será la disuasión. Interesa señalar que la probabilidad de revisión judicial depende, a su vez, de varias circunstancias, de entre las cuales destaca la utilidad esperada - los eventuales costes y beneficios- que para los afectados por la decisión supone recurrirla ante los Tribunales, que a su vez dependerá de la probabilidad de que éstos estimen el recurso.

En tercer lugar, cuanto mayores sean los beneficios que para las autoridades administrativas se deriven de infringir la ley, más difícil será que la amenaza del control judicial las disuada de escoger esta alternativa.

También tendrán cierto impacto sobre la disuasión, en cuarto lugar, los errores cometidos por los Tribunales al enjuiciar la actividad administrativa. Tanto las estimaciones erróneas de recursos contencioso-administrativos - falsos positivos- como las inadmisiones o desestimaciones equivocadas -falsos negativos- minan el efecto 
disuasorio del control judicial ${ }^{19}$. Las primeras, porque incrementan el coste esperado - es decir, reducen el atractivo- que para la Administración tiene respetar el ordenamiento jurídico. Las segundas, porque minoran el coste esperado que para ella supone violarlo. Cuanto más grave sea el riesgo de estos errores, menor será, por lo tanto, la disuasión.

De otro lado, al resolver casos en los que se discute si ciertas actuaciones administrativas son o no conformes a Derecho, los Tribunales generan información acerca de cómo deben ser interpretadas y aplicadas las normas jurídicas que regulan dichas actuaciones, clarificando su alcance, colmando sus eventuales lagunas, resolviendo las dudas interpretativas que plantean en determinados casos, etc. Esta información puede y debe ser utilizada en casos similares para prevenir ilegalidades. Las autoridades administrativas podrán tenerla en cuenta con el fin de evitar cometer los errores no intencionados en los que probablemente hubieran incurrido si los Tribunales no hubieran clarificado el alcance de las normas reguladoras de su actividad. También los órganos jurisdiccionales encargados de juzgar casos semejantes podrán aprovecharla, a fin de interpretar y aplicar correctamente esas mismas normas jurídicas. Y ya sabemos que la reducción del número de los errores judiciales mejora la eficacia disuasoria de la Justicia administrativa y, en consecuencia, tiende a minorar, en términos cuantitativos y cualitativos, las infracciones cometidas por las Administraciones públicas.

B) Incremento del riesgo de decisiones desviadas

El más serio inconveniente de otorgar discrecionalidad a las Administraciones públicas es que éstas pueden aprovecharla para cometer abusos, para desviarse de la solución que mejor satisface los intereses generales. Al limitar el control judicial y su eficacia preventiva, esa discrecionalidad favorece que dichas organizaciones ejerzan ilegalmente sus potestades. Además, el subsiguiente aumento de estas infracciones puede provocar, en determinadas circunstancias, un incremento de la litigiosidad y, paradójicamente, incluso del número de ocasiones en las que los Tribunales declaran la ilegalidad de actuaciones administrativas, con los costes que todo ello implica.

Los jueces también pueden cometer arbitrariedades y abusos, ciertamente, pero el riesgo de que esto suceda es, en líneas generales, menor que el de que las autoridades administrativas hagan lo propio.

Ello se explica porque nuestro sistema jurídico articula incontables medidas singularmente estrictas dirigidas a enervar la negativa influencia que presiones e incentivos espurios pueden tener sobre la actividad judicial. Se pretende garantizar con ellas que los órganos jurisdiccionales actúen únicamente sometidos al imperio de

9 Vid., mutatis mutandis, PNG, I.P.L. (1986); POLINSKY, A.M. y SHAVELL, S. (2000, pp. 60 y ss.). 
la ley (art. $117 \mathrm{CE}$ ). En palabras del Tribunal Constitucional, se trata de «asegurar que la pretensión sea decidida exclusivamente por un tercero ajeno a las partes y a los intereses en litigio y que se someta exclusivamente al ordenamiento jurídico como criterio de juicio. Esta sujeción estricta a la Ley supone que esa libertad de criterio en que estriba la independencia judicial no sea orientada a priori... por motivos ajenos a la aplicación del Derecho» ${ }^{20}$. Piénsese en: la inamovilidad de los jueces; su régimen de incompatibilidades; ciertas restricciones impuestas al ejercicio de algunos de sus derechos fundamentales; la reserva de ley establecida para regular su estatuto jurídico; el sistema de autogobierno del Poder judicial diseñado por la Constitución; el hecho de que los jueces carezcan, normalmente, de discrecionalidad para elegir los casos que van a decidir; su obligación de abstenerse de conocer de aquellos casos en los que, por su concreta relación con las partes o con el objeto del proceso, se hallen en una situación en vista de la cual pueda temerse razonablemente que no actuarán de manera objetiva, etc.

Estas garantías establecidas para asegurar la objetividad y sujeción al Derecho de la actividad judicial son mucho más numerosas y estrictas que las dispuestas respecto de la administrativa, lo que determina que el riesgo de desviaciones sea menor en el primer caso.

Repárese, por ejemplo, en que los grupos de presión pueden «capturar» más fácilmente a las autoridades administrativas que a los jueces. De un lado, por el peculiar estatuto jurídico - régimen de incompatibilidades, inamovilidad, retribuciones, etc.- al que están sometidos éstos, que los aísla considerablemente frente a las presiones externas. De otro lado, porque el hecho de que el poder judicial constituya una organización sumamente descentralizada, integrada por miles de órganos jurisdiccionales independientes, cuya capacidad de coordinarse y de escoger los casos que han de juzgar es muy limitada, dificulta enormemente su captura. Los costes de presionar a las autoridades competentes para que éstas actúen en un determinado sentido se incrementan cuanto más elevado es el número de ellas. Y, obviamente, cuanto mayor es la facilidad para «capturar» a una autoridad pública y lograr que ésta adopte decisiones que favorecen los intereses especiales de un grupo de presión, más elevadas serán las «recompensas» que el mismo esté dispuesto a ofrecer a fin de ganarse el favor de aquélla y, por lo tanto, mayor será el peligro de arbitrariedades y abusos. Un riesgo superior de ser capturado determina un riesgo superior de adoptar decisiones desviadas.

20 ATG (Pleno) 26/2007, de 5 de febrero, FJ 3. 


\section{Beneficios de la discrecionalidad administrativa}

A) Reducción de los costes del control judicial

La discrecionalidad administrativa, en tanto en cuanto supone una limitación del control judicial, tiende también a reducir los costes que éste conlleva.

\section{a) Costes de procedimiento}

Para verificar si la actuación administrativa impugnada es o no conforme con el ordenamiento jurídico, los Tribunales, las partes y sus defensores han de invertir tiempo y esfuerzo, recursos que ya no podrán destinar a otros fines alternativos.

Cabe razonablemente pensar que estos costes están en función creciente de la intensidad del control judicial. Cuanto más intenso y profundo sea el análisis efectuado por los Tribunales para averiguar si la decisión administrativa impugnada se ajusta o no a Derecho, mayores serán el tiempo y el esfuerzo que esta tarea les supondrá. La práctica de una prueba pericial, por ejemplo, podrá proporcionar al juez elementos de juicio que le permitan ser más incisivo a la hora de enjuiciar la resolución administrativa recurrida, pero también conlleva unos costes que alguien ha de sufragar.

\section{b) Costes de los errores judiciales}

Los Tribunales pueden equivocarse al juzgar la legalidad de la actuación sometida a su consideración. Pueden declararla ilegal cuando en realidad es legal o declararla conforme a Derecho cuando en verdad lo infringe. En cualquiera de los dos casos, la situación resultante puede menoscabar bienes jurídicamente protegidos.

La magnitud de los costes esperados de estos errores depende de diversos factores, entre los que destacan: la importancia de los intereses en juego; la probabilidad de equivocarse; y lo costoso que resulte rectificar $-\mathrm{v}$. gr. mediante una reforma legislativa o un giro jurisprudencial- el error judicial cometido.

B) La discrecionalidad administrativa como instrumento de minimización del riesgo de errores

El principal beneficio que, en determinadas circunstancias, se deriva de reconocer a la Administración un cierto margen de apreciación o maniobra es, seguramente, que ello permite incrementar la probabilidad de que se establezcan las soluciones que satisfacen mejor los intereses de los ciudadanos. Ello obedece a que muchas veces la Administración competente posee mayor capacidad - por su composición, sus procedimientos de actuación, sus medios materiales y personales, etc.que los Tribunales para decidir acertadamente en el caso considerado. 
La discrecionalidad administrativa puede constituir, pues, un instrumento de minimización del riesgo de errores. Con ella puede minorarse la probabilidad de que el aparato estatal -tras la actuación sucesiva de la Administración y los jueces-arroje resultados erróneos, desacertados, ilegales, perjudiciales para los intereses públicos. La reducción de ese riesgo puede generar a su vez otros beneficios: (i) disminuir los costes de litigación del sistema, en la medida en que -cabe suponer- las situaciones ineficientes, que no satisfacen óptimamente dichos intereses, tienen una mayor probabilidad de ser impugnadas que las decisiones acertadas, eficientes; (ii) y mejorar el efecto disuasorio del control judicial, pues, según hemos visto, los errores cometidos en su ejercicio lo minan.

Finalmente, el hecho de que los Tribunales muestren un mayor grado de deferencia hacia las decisiones administrativas también puede minorar el número de casos en los que éstas son impugnadas y declaradas ilegales, lo que haría menguar todavía más los costes de litigación y, también, aquellos costes en los que hay que incurrir, después de la declaración de ilegalidad, para alterar el statu quo creado por aquéllas. Conviene subrayar, sin embargo, que no es necesario que así ocurra. Por ejemplo, un aumento de la deferencia judicial también podría provocar que la Administración se aprovechara de ella para interpretar la ley de una manera más cuestionable o implausible, lo que a su vez podría dar lugar a que un mayor número de resoluciones administrativas fueran recurridas por los afectados e incluso anuladas por los Tribunales ${ }^{21}$.

C) La discrecionalidad administrativa como instrumento de legitimación

La discrecionalidad administrativa también puede servir para aumentar la legitimidad de determinadas decisiones, es decir, para incrementar su aceptación por parte de sus destinatarios. Este efecto se producirá y será tanto más fuerte cuanto mayor sea la diferencia de legitimidad entre el órgano administrativo autor de la decisión en cuestión y el Tribunal encargado de revisarla. Esta diferencia será máxima, seguramente, cuando los miembros de ese órgano hayan sido elegidos mediante sufragio universal.

El incremento en la aceptación que determinadas decisiones administrativas susciten entre sus destinatarios seguramente facilitará su ejecución y reducirá la probabilidad de que sean impugnadas, con el consiguiente ahorro de recursos para todos los implicados.

${ }_{21} \quad$ Vid., mutatis mutandis, GIVATI, Y. (2009). 


\section{EL ALGANGE ÓPTIMO DE LA DISGREGIONALIDAD ADMI- NISTRATIVA Y, POR ENDE, DE SU CONTROL JUDICIAL}

\section{Factores determinantes}

Los Tribunales deberían ponderar todas esas ventajas y desventajas a la hora de reconocer un mayor o menor margen de apreciación a la Administración y juzgar si sus decisiones se mantienen dentro del mismo. A estos efectos, deberían tener en cuenta que ese balance ventajas-desventajas puede arrojar resultados muy diferentes en función de varios factores:

En primer lugar, de la diferencia existente entre la autoridad administrativa artífice de la decisión enjuiciada y el Tribunal encargada de revisarla en punto a la capacidad para alcanzar en el caso considerado la mejor solución para los intereses públicos o, dicho de otra manera, para minimizar el número y la gravedad de los errores cometidos a este respecto. Sólo si dicha autoridad tiene mayor capacidad -v. gr., por poseer mejores conocimientos técnicos-que el Tribunal para garantizar el acierto de una decisión como la enjuiciada estará justificado que aquél muestre un cierto grado de deferencia hacia ésta. Cuanto mayor sea la brecha en favor de la autoridad administrativa, mayor deberá ser, ceteris paribus, su margen de apreciación y, correlativamente, la deferencia judicial.

En segundo término, resulta relevante la incertidumbre existente acerca de si decisión cuestionada es la que más conviene al interés público. Cuanto mayor sea esta incertidumbre, mayor espacio de maniobra deberá concederse a la Administración, siempre que ésta tenga mayor capacidad de tomar una decisión acertada, pues así se reduce el riesgo de cometer errores. Si el Tribunal competente, a la vista de la información disponible, pudiera verificar con certeza absoluta cuál es la solución que logra un justo equilibro entre todos los intereses afectados, no tendría sentido alguno darle a la Administración la posibilidad de optar por otra alternativa. La magnitud de la incertidumbre dependerá, a su vez, de otras variables, cuando menos de: (i) la densidad con la que el legislador haya predeterminado el sentido de las decisiones que la Administración puede tomar; y (ii) el grado de complejidad fáctica del caso.

También ha de influir, en tercer lugar, la plausibilidad sustancial de la decisión administrativa enjuiciada. Dicha plausibilidad puede definirse como la distancia existente entre la solución a la que ha llegado la Administración al apreciar los hechos, interpretar el Derecho y aplicarlo al caso considerado y la solución a la que llegaría el Tribunal a la vista de la información disponible si tuviera que decidir ex novo. Cuanto menos plausible sea la decisión revisada, menor debería ser la deferencia con la que los Tribunales la juzguen, pues entonces mayor es la probabilidad de que no se haya alcanzado con ella la solución óptima para los intereses públicos. 
Otro factor relevante, en cuarto lugar, son las garantías organizativas, procedimentales y formales observadas en el caso concreto por la Administración para decidir. Cuanto más rigurosas hayan sido - v. gr. los estudios realizados y las pruebas practicadas con el fin de averiguar mejor los hechos relevantes, así como los argumentos aducidos para justificar la decisión- mayor habrá de ser el referido margen de apreciación. La razón es que el cumplimiento de estas garantías incrementa a priori la probabilidad de resolver acertadamente. Ello no quita que, a veces, pueda comprobarse ex post que la inobservancia de algunas de esas garantías, incluso de las prescritas por la ley, no disminuyó dicha probabilidad, por ejemplo, porque la Administración tomó la única decisión conforme a Derecho que cabía tomar, en cuyo caso la infracción debería considerarse como «no invalidante $»^{22}$. Nótese que la plausibilidad sustancial y las referidas garantías tienen, por consiguiente, un cierto carácter sustitutivo o intercambiable: cuanto menor sea aquélla, más rigurosas habrán de ser éstas para que la decisión pueda ser considerada válida, y viceversa ${ }^{23}$.

La legitimidad democrática del órgano administrativo autor de la decisión enjuiciada, en quinto lugar, también debería tomarse en consideración ${ }^{24}$. Cuanto mayor sea esta legitimidad, más aceptables por los ciudadanos serán, a priori, sus decisiones y, adicionalmente, mejor alineados estarán sus preferencias con las de la mayoría de ellos, por lo que el riesgo de que incurran en -ciertas-desviaciones será menor y, en consecuencia, el margen de maniobra que se les otorgue habrá de ser más amplio.

Otro factor importante es, precisamente, el riesgo de que, por las razones que sean, la Administración, al llevar a cabo la actuación cuestionada, se desvíe de la solución más conveniente para el interés público y prescrita por el Derecho. Cuanto mayor sea ese riesgo, menor habrá de ser la deferencia judicial.

La relevancia de los intereses en juego juega un papel ambivalente. Cuanto más relevantes sean éstos, mayor gravedad podrán revestir los daños causados por los errores cometidos y, por lo tanto, más necesidad habrá de que la decisión sea adoptada por la autoridad que cuenta con mayor capacidad para acertar, que muchas veces es la administrativa. Pero, por otro lado, más graves serán también los daños ocasionados por las arbitrariedades eventualmente cometidas por la Administración. Así las cosas, una solución óptima para los casos en los que los intereses afectados revisten una gran trascendencia puede consistir en que los jueces reconozcan a la Administración un ancho margen para actuar, con la condición de que extremen las garantías orga-

\footnotetext{
22 Vid., por todos, GARCÍA LUENGO, J. (2016) y DOMÉNECH PASCUAL, G. (2017).

23 Vid. STEPHENSON, M.C. (2006).

24 En contra, GARCÍA DE ENTERRÍA, E. (2009); BELTRÁN DE FELIPE, M. (1995, pp. 221 y ss.); DESDENTADO DAROCA, E. (1999, pp. 205 y ss.).
} 
nizativas, procedimentales y formales observadas a fin de asegurar el acierto de sus decisiones.

También debe tenerse en cuenta si los costes de los errores en los que los Tribunales pueden incurrir al revisar una actuación administrativa difieren en función de si la decisión judicial declara su ilegalidad (incurren en un falso positivo) o su legalidad (falso negativo). Cuanto más costosos sean los falsos positivos en relación con los falsos negativos, mayor habrá de ser la deferencia otorgada a la Administración. Esta asimetría puede obedecer a diversas causas. Por ejemplo, a que los costes de rectificación son mayores en un caso que en el otro. Se ha señalado que, en nuestro Derecho, rectificar la anulación errónea de una ley es mucho más difícil que hacer lo propio con el error cometido al declarar válida una norma legal que en verdad es inconstitucional. La corrección de los errores del primer tipo requiere que el Tribunal Constitucional cambie su jurisprudencia sobre el particular, lo que sólo puede ocurrir si el legislador vuelve a dictar preceptos idénticos a los previamente declarados inconstitucionales, lo cual es dudoso que pueda hacerse ${ }^{25} \mathrm{y}$, en cualquier caso, resulta políticamente muy costoso, ya que podría interpretarse como un acto de desobediencia. Para rectificar los falsos negativos, también hace falta que el Tribunal Constitucional tenga la oportunidad de cambiar su opinión, pero esto es mucho más fácil que suceda, pues, desestimado un recurso o cuestión de inconstitucionalidad formulados contra un determinado precepto legal, cualquier juez puede volver a plantear una cuestión contra el mismo precepto fundada en motivos coincidente ${ }^{26}$. Esta asimetría es una de las razones que justificaría el otorgamiento a las leyes de una suerte de «presunción de validez» o, dicho con otras palabras, que exigiría restringir el poder otorgado al Tribunal Constitucional de anular las leyes sometidas a su juicio, de manera que éstas sean consideradas válidas cuando su conformidad con la Constitución resulte dudosa ${ }^{27}$.

Lo mismo vale respecto de los reglamentos. No es sencillo rectificar su anulación errónea, pues para ello se necesita que la Administración reitere los preceptos declarados inválidos, lo que parece estar prohibido por el artículo 103.4 LJCA, al margen de los costes políticos y de procedimiento que la elaboración de la «nueva» disposición implicaría. Para corregir una declaración de validez errónea, en cambio, tan sólo se requiere que algún Tribunal estime, al conocer de un recurso interpuesto contra un acto dictado en aplicación del reglamento en cuestión, que éste es ilegal. De hecho, esta posibilidad viene inequívocamente contemplada por el artículo 26.2 LJCA. Ello justificaría igualmente limitar en cierta medida el poder de los Tribunales de anular las disposiciones reglamentarias sometidas a su juicio. Si anularlas

\footnotetext{
25 Sobre el tema, en sentido afirmativo, VIVER PI-SUNYER, C. (2013).

Vid., a contrario sensu, el art. 38 LOTC, así como la STC 55/1996, de 28 de marzo, FJ 2.

FERRERES COMELLA V. (1997, pp. 199 y ss.).
} 
es ceteris paribus más costoso que declararlas válidas, convendrá decantarse por esta segunda alternativa en los casos dudosos, hasta cierto punto.

La asimetría del coste de los errores judiciales también puede deberse a que los costes de los errores en los que eventualmente incurra la actuación administrativa impugnada son asimismo asimétricos. El Tribunal Supremo ha declarado, por ejemplo, que el «rigor del control» judicial de las resoluciones adoptadas en procedimientos sancionadores en materia de defensa de la competencia ha de ser, en principio, «más estricto» cuando se revisan sanciones que cuando se examinan resoluciones exculpatorias o de archivo $^{28}$. El Tribunal Supremo no se detiene a justificar esta doctrina, pero el fundamento de la misma puede verse en la idea, que inspira la configuración del moderno Derecho penal, de que las condenas erróneas son socialmente más costosas que las absoluciones erróneas. De acuerdo con la celebérrima sentencia de BLackstone: «It is better that ten guilty persons escape than that one innocent suffer» ${ }^{29}$.

Finalmente, debe señalarse que el hecho de que el legislador, de manera explícita o al menos inequívoca, haya establecido que la Administración dispone de discrecionalidad para adoptar ciertas decisiones constituye un factor determinante, por cuanto clarifica el problema. La ley reduce de esa manera el arbitrio que los Tribunales tienen para determinar la existencia y la amplitud del espacio decisorio otorgado a la Administración.

\section{El factor estratégico}

A la hora de ponderar las consecuencias que sus alternativas de decisión pueden tener para los intereses legítimos en juego, los Tribunales deberían tener muy presente cómo reaccionarán probablemente tanto la Administración como el legislador frente a cada una de las referidas alternativas ${ }^{30}$. La razón es obvia: la manera, positiva o negativa, en que sus decisiones afectan a los referidos intereses depende, en gran medida, de cuáles sean estas reacciones.

Estas consideraciones estratégicas no son frecuentes, pero tampoco del todo extrañas, en la jurisprudencia de nuestros Tribunales. Una razón de este tipo subyace, por ejemplo, en el argumento o «principio» según el cual nadie puede aprovecharse de su propia torpeza (nemo auditur propriam turpitudinem allegans), ocasionalmente utilizado por aquéllos ${ }^{31}$. Si se interpretara la ley de manera que quien incumple sus

28 Vid. la STS de 12 de junio de 2012 (rec. 2069/2009).

29 BLACKSTONE, W. (1769, p. 352). Esta idea ha sido expresada por otros muchos autores y de diversas maneras a lo largo de la historia. Véase al respecto VOLOKH, A. (1997).

30 Por descontado, también deberían tener en cuenta las reacciones de otros actores implicados, como los particulares afectados por las correspondientes leyes y decisiones administrativas.

31 Vid. REBOLLO PUIG, M. (2002) y ARANA GARCÍA, E. (2003). 
obligaciones obtuviera un provecho de ello, se estaría «premiando e incentivando» el incumplimiento, lo que en principio hay que evitar ${ }^{32}$.

Con mayor razón, si cabe, los Tribunales deberían revisar y ajustar, al alza o a la baja, su nivel de deferencia a la vista de cuál haya sido efectivamente la respuesta dada por las autoridades administrativas a sus decisiones. De hecho, es probable que así lo hagan en muchos casos. Sirva el ejemplo del control judicial de los decretos-leyes. La enorme condescendencia que el Tribunal Constitucional mostró durante décadas a la hora de enjuiciarlos - y en particular, de verificar si concurría la «extraordinaria y urgente necesidad» prevista en el art. 86.1 CE- propició que el Gobierno abusara cada vez más del poder de dictar estas normas, hasta que los excesos llegaron a extremos manifiestamente inaceptables ${ }^{33}$, lo que ha acabado provocando que dicho Tribunal se haya vuelto, en líneas generales, más severo al juzgarlas ${ }^{34}$.

Cabe pensar, no obstante, que a veces los Tribunales no tienen suficientemente en cuenta a estos efectos cuál es la reacción esperable de la Administración y, sobre todo, del legislador. Piénsese, por ejemplo, en la jurisprudencia relativa al régimen disciplinario de funcionarios y estudiantes universitarios. Es muy dudoso que, una vez aprobada la Constitución española, las infracciones graves y leves de los primeros puedan tipificarse en una norma reglamentaria, como lo es el todavía vigente RD 33/1986, y que el vetusto Reglamento de Disciplina Académica de 1954 satisfaga las exigencias del principio de tipicidad. Sin embargo, el Tribunal Supremo, presionado seguramente por el «vacío legal» que se originaría si declarara la invalidez de tales normas, se ha resistido en numerosas ocasiones a considerarlas contrarias a la Constitución o derogadas ${ }^{35}$. Es posible que aquí el Tribunal haya evaluado de una manera algo miope las consecuencias de sus alternativas de decisión. Anular los reglamentos en cuestión implicaba generar una situación de impunidad durante un tiempo, hasta que el legislador interviniera para colmar el vacío existente. Declararlos válidos suponía que, mientras el legislador no regulara esta materia, se mantenía vigente y había que aplicar una norma seguramente inconstitucional. Nótese que el coste esperado de cada una de estas soluciones dependía críticamente de lo que previsiblemente tardara el legislador en acabar con la insatisfactoria situación que ambas dejaban.

\footnotetext{
32 Vid. la STS de 23 de octubre de 2017 (1592/2017).

33 Vid., por ejemplo, las críticas de ARANA GARCÍA, E. (2013); MARTÍN REBOLLO, L. (2015); ARAGÓN REYES, M. (2016).

34 Vid. las SSTC 68/2007, de 28 de marzo; 31/2011, de 17 de marzo; 137/2011, de 14 de septiembre; 1/2012, de 13 de enero; 27 y 29/2015, de 19 de febrero; 196 y 199/2015, de 24 de septiembre; $211 / 2015$, de 8 de octubre; 230/2015, de 5 de noviembre; 26/2016, de 18 de febrero; 38/2016, de 3 de marzo; 70/2016, de 14 de abril; 125 y 126/2016, de 7 de julio; 169/2016, de 6 de octubre; 73/2017, de 8 de junio; y 150 y 152/2017, de 21 de diciembre.

35 Vid., por ejemplo, la STS de 30 de marzo de 2017 (rec. 3300/2015), comentada por MARINA JALVO, B. (2017), así como TARDÍO PATO, J. A. (2018).
} 
Pues bien, es muy razonable pensar que la anulación judicial hubiera desencadenado una reacción más o menos inmediata del legislador, que difícilmente hubiera tolerado que la referida impunidad se prolongara más allá de lo indispensable para colmar la laguna. En cambio, podía esperarse, como de hecho así ha ocurrido, que si los reglamentos disciplinarios cuestionados se consideraban válidos el legislador iba a tardar mucho tiempo en sustituirlos por otros nuevos, toda vez que esta sustitución le reportaba una escasa, por no decir negativa, rentabilidad política.

\section{Poderes del juez frente a las decisiones administrativas ilegales}

Constatada la ilegalidad de la decisión administrativa revisada, los Tribunales tienen varias alternativas. Pueden: (i) estimar que incurre en una irregularidad no invalidante y, en consecuencia, dejar intactos los efectos jurídicos que la misma hubiese pretendido producir; (ii) anularla y dejar que la Administración considere la posibilidad de adoptar una nueva decisión, esta vez conforme a Derecho; (iii) anularla y obligar a la Administración a decidir otra vez, en su caso bajo ciertas condiciones; o (iv) anularla y sustituirla por una regulación establecida por el propio órgano jurisdiccional.

Si se acredita que la irregularidad -v. gr. de procedimiento- no influyó sobre el contenido de la decisión adoptada o, incluso, que ésta era la única que la Administración podía y debía tomar, anularla resultaría antieconómico. De hecho, los Tribunales suelen interpretar el artículo 48.2 LPAC y otros preceptos similares en el sentido de que en estos casos la irregularidad cometida ha de calificarse como no invalidante $^{36}$.

Análogamente, los Tribunales, si tienen suficientes elementos de juicio para precisar cuál es la única solución que, habida cuenta de las circunstancias del caso, debía haber sido establecida por la Administración y no lo fue - es decir, si la discrecionalidad se «reduce a cero»-, tendrán que establecerla ellos mismos en sustitución de la decisión administrativa anulada, siempre, claro está, que alguna de las partes así lo hubiera pretendido. Devolver el caso a la Administración demandada para que ésta resuelva también sería antieconómico y constituiría una denegación de justicia contraria al derecho a la tutela judicial efectiva ${ }^{37}$.

Si la información disponible en el proceso no basta para concluir cuál era la decisión más conveniente para los intereses públicos y que debía haber sido adoptada por la autoridad administrativa competente -v. gr. porque todavía hay que recono-

36 Vid. GARGía LUENGO, J. (2016) y DOMÉNECH PASGUAL, G. (2017).

37 Vid., por todos, BAÑO LEÓN, J. M. (2011). 
cerle un cierto margen de discrecionalidad-, los Tribunales deberán declarar inválida la actuación impugnada, sin posibilidad de sustituirla por otra. La razón es obvia: el legislador le ha encomendado dicha tarea a la Administración, por cuanto ésta se encuentra mejor situada que aquéllos para precisar cuál es la solución óptima. En ocasiones, además, podrán condenar a la Administración a actuar, si la misma tiene una obligación en este sentido y alguna de las partes así lo ha pretendido. E incluso podrán especificar, en una suerte de sentencia-marco, los requisitos a los que habrá de ajustarse la actuación administrativa debida ${ }^{38}$. Otras veces, por el contrario, a la Administración no le estará permitido adoptar una nueva decisión sobre el fondo ${ }^{39}$, por ejemplo, porque la posibilidad de hacerlo ha prescrito ${ }^{40} \mathrm{o}$, en los procedimientos sancionadores, porque ello supondría una vulneración del principio non bis in ídem en su vertiente formal ${ }^{41}$.

En los casos en los que la Administración vuelve a decidir sobre el fondo del asunto, es frecuente que la nueva resolución tenga el mismo contenido que la anterior, en su día anulada por padecer algún vicio formal o de procedimiento que ahora supuestamente se ha subsanado. Aquí es inevitable que se susciten dudas acerca de si la nueva decisión es o no conforme a Derecho ${ }^{42}$. Muchas veces cabe sospechar que las autoridades administrativas no aprovechan efectivamente las oportunidades que les brinda el nuevo procedimiento para mejorar el acierto de su decisión, modificándola si es necesario. Ello, de un lado, por factores de índole psicológica. Los sesgos de la confirmación ${ }^{43}$ y del statu quo ${ }^{44}$, así como la disonancia cognitiva provocada por rectificar una decisión sostenida y defendida públicamente, pueden propiciar que tales autoridades no reconsideren como sería deseable su posición inicial y se mantengan 88 y ss.).

38 Vid. HUERGO LORA, A. (2000, pp. 283 y ss.) y DE VICENTE DOMINGO, R. (2014, pp.

39 La posibilidad de que la Administración reitere liquidaciones tributarias ha generado una gran polémica. El Tribunal Supremo la admite con matices. Vid., entre otras, las SSTS de 19 de noviembre de 2012 (rec.1215/2011) y 15 de junio de 2015 (rec. 1551/2014). En la doctrina, vid., por todos, SESMA SÁNCHEZ, B. (2017).

40 Una cuestión interesante es la de si los procedimientos que se resuelven con un acto luego anulado interrumpen la prescripción. En la STS de 19 de noviembre de 2012 (rec. 1215/2011) se afirma que sólo se produce la interrupción si el acto en cuestión padecía un vicio de anulabilidad, no de nulidad. Sobre el tema, vid. SESMA SÁNCHEZ, B. (2017).

41 Así lo declaran (a veces, incidentalmente) las SSTS de 26 de marzo de 2012 (rec. 5827/2009), 7 de abril de 2014 (rec. 3714/2011), 11 de abril de 2014 (rec. 164/2013), 29 de septiembre de 2014 (rec. 1014/2013), 27 de enero de 2016 (rec. 3735/2014) y 27 de marzo de 2017 (rec. 3570/2015). Vid., mutatis mutandis, DOMÉNECH PASCUAL, G. (2007).

42 Vid. el caso resuelto por la STS (Pleno de la Sala $3^{\text {a }}$ ) de 27 de junio de 2017 (rec. 4942/2016). Sobre algunos de los problemas que plantea esta reiteración, vid. HUERGO LORA, A. (2001); ALONSO MAS, M' J. (2003); LOZANO SERRANO, C. (2013).

43 Vid., por ejemplo, NICKERSON, R.S. (1999).

44 Vid., por ejemplo, SAMUELSON, W. y ZEGKHAUSER, R. (1988). 
en ella a pesar de que la nueva información disponible aconseja cambiarla ${ }^{45}$. De otro lado, los costes privados que para dichas autoridades suele conllevar la alteración del statu quo creado por la decisión inicial desincentivan su modificación.

Este problema podría ser combatido de dos maneras. Los Tribunales, en primer lugar, podrían rebajar hasta cierto punto el umbral de certeza a partir del cual consideran que en el caso enjuiciado sólo hay una solución válida, que deben establecer ellos mismos en sustitución de la anulada, eliminando así la posibilidad de que ésta sea reiterada. La pega es que semejante solución sólo vale para los casos marginales, donde es dudoso que la discrecionalidad administrativa se haya reducido a cero, y además supone un sacrificio para los valores que justifican la existencia de esta discrecionalidad. Los Tribunales, en segundo lugar, podrían condicionar la validez de la reiteración a la observancia de garantías formales y procedimentales especialmente estrictas y, en particular, a una motivación singularmente cuidada que permitiese despejar las sospechas de arbitrariedad. Esta solución tiene la ventaja de que vale para cualquier caso de reiteración, pero la desventaja de que exigir un «plus de motivación» no constituye una barrera insalvable frente a las reiteraciones que no satisfacen de manera óptima los intereses generales. Los Tribunales suelen optar por esta segunda alternativa. Sirva como ejemplo la jurisprudencia que se muestra extraordinariamente reacia a admitir la posibilidad de convalidar licencias urbanísticas $-y$, por ende, las edificaciones ilegalmente construidas a su amparo-mediante una modificación del planeamiento ${ }^{46}$.

\section{UNA TEORÍA SUSTANCIALMENTE ACORDE GON LA JURIS- PRUDENGIA}

Con independencia de cuál sea el discurso con el que muchas veces los Tribunales visten sus decisiones, lo cierto es que, de facto, el sentido de éstas suele ajustarse, en líneas generales, a los criterios expuestos en el epígrafe anterior.

En efecto, nuestros Tribunales reconocen a veces a las Administraciones públicas un cierto «margen de apreciación» para interpretar y aplicar algunas disposiciones legales, aunque en éstas nada se diga explícitamente a este respecto. En sentido similar, en ocasiones se dice que determinadas decisiones administrativas gozan de

45 Vid., mutatis mutandis, STERN, S. (2002), donde se analiza en qué medida estos factores pueden minar el valor del trámite de información pública en los procedimientos de elaboración de reglamentos, al provocar una excesiva cerrazón en los artífices del proyecto normativo frente a los comentarios formulados por el público, y se proponen varias soluciones.

${ }_{46}$ Criticada por SANTAMARÍA PASTOR, J.A. (2014). 
una suerte de «presunción de acierto» ${ }^{47}$. De resultas de ello, deben ser dadas por válidas a menos que se evidencie que las soluciones alcanzadas en la apreciación de los hechos o en la interpretación y aplicación del ordenamiento jurídico rebasan un cierto nivel de implausibilidad. Para declarar la invalidez, hay que detectar un error «manifiesto», «notorio», «ostensible», «patente», «claro e inequívoco» ${ }^{48}$. El Tribunal de Justicia de la Unión Europea, en sentido similar, habla de «error manifiesto de apreciación» ${ }^{49}$.

$\mathrm{Al}$ objeto de justificar la existencia de ese margen de apreciación o "presunción de acierto» se aducen varias razones. La más recurrente es la que podríamos denominar de la complejidad técnica. En ocasiones, los órganos administrativos que han participado en la elaboración de la decisión impugnada cuentan con mejores conocimientos especializados y están mejor situados que los Tribunales para resolver acertadamente determinadas cuestiones de gran complejidad técnica que plantea dicha decisión ${ }^{50}$. Tal es la razón que subyace en la jurisprudencia sobre la llamada «discrecionalidad técnica», elaborada sobre todo en relación con la valoración de los méritos y la capacidad de los candidatos en los procedimientos de acceso al empleo público y de provisión de puestos de trabajo. Esta doctrina ha evolucionado notablemente $^{51}$. Hace unos años, las apreciaciones técnicas de los correspondientes órganos administrativos eran prácticamente irrevisables por los Tribunales, hasta el punto de que se excluía a priori la posibilidad de practicar pruebas periciales dirigidas a evidenciar su carácter erróneo ${ }^{52}$. Esta jurisprudencia era muy desafortunada: en primer lugar, porque propiciaba que dichos órganos, conscientes de que sus apreciaciones técnicas eran de facto absolutamente inmunes al control judicial, cometieran arbitrariedades al efectuarlas ${ }^{53}$; y, en segundo término, porque en ocasiones es relativamente

47 Vid., entre otras, las SSTS 13 de febrero de 1996 (rec. 443/1995), 11 de noviembre de 1996 (rec. 1844/1989), 10 de febrero de 1998 (rec. 2960/1992), 18 de febrero de 2003 (rec. 646/2000) y 30 de enero de 2008 (rec. 9976/2004).

${ }_{48}$ Vid., además, de las citadas en la nota anterior, las SSTS de 16 de diciembre de 2014 (rec. 3157/2013), 23 de diciembre de 2014 (rec. 3462/2013) y 16 de marzo de 2016 (rec. 526/2015).

49 Vid., entre otras muchas, las SSTJUE de 15 de octubre de 2009 (Enviro Tech, C-425/08, § 47) y 8 de julio de 2010 (Afton Chemical Limited, C-343/09, § 28).

50 Vid., entre otras, la STS de 16 de diciembre de 2014 (rec. 3157/2013); las SSTJUE de 21 de enero de 1999 (Upjohn, C-120/97, § 34), 15 de octubre de 2009 (Enviro Tech, C-425/08, § 47) y 8 de julio de 2010 (Afton Chemical Limited, C-343/09, § 28); y la STEDH de 8 de julio de 2003 (Hatton y otros c. Reino Unido, 36022/97, §§ 97 y ss.).

51 Vid. LÁZARO ALBA, E. y GONZÁLEZ BOTIJA, F. (2005); GARCÍA ÁLVAREZ, G. (2012); RIVERO YSERN, E. y RIVERO ORTEGA, R. (2012); FERNÁNDEZ RODRÍGUEZ, T.R.(2015).

52 Vid. la STC 34/1995, de 6 de febrero.

53 Como advierte MESTRE DELGADO, J.F. (2016, p. 120), «ante la ausencia de control judicial, se ensanchaban los fenómenos de incorrecto ejercicio de las potestades». 
poco costoso para los Tribunales detectar y declarar ciertos errores en los que dichas apreciaciones han podido incurrir.

Hoy ya no se excluye de entrada la posibilidad de revisar judicialmente el contenido de tales apreciaciones, y el rigor exigido a la motivación de las resoluciones administrativas adoptadas sobre la base de las mismas se ha intensificado muy considerablemente $^{54}$. No obstante lo cual, los Tribunales siguen reconociendo aquí a las autoridades administrativas un cierto margen de apreciación ${ }^{55}$. Y, desde luego, así sucede también en otros ámbitos - v. gr. en los de la regulación de la economía y el control de riesgos tecnológicos--, donde la complejidad técnica y la incertidumbre en las que ha de moverse la Administración son mucho más acusadas que en el del acceso al empleo público ${ }^{56}$.

Cuanto mayor es esta complejidad o, más exactamente, la diferencia de capacidad o brecha cognoscitiva entre la Administración y los Tribunales, tendencialmente más amplio es el margen de apreciación que éstos reconocen a la misma. De ahí que, por poner algunos ejemplos: (i) caigan «fuera del ámbito de dicha discrecionalidad técnica las apreciaciones que, al estar referidas a errores constatables con simples comprobaciones sensoriales o con criterios de lógica elemental o común, no requieren esos saberes especializados» ${ }^{57}$; (ii) el control judicial de las decisiones administrativas sobre acceso al empleo público suele ser más incisivo cuando se revisa la evaluación de conocimientos jurídicos, respecto de los cuales los jueces son expertos, que cuando se hace lo propio con saberes de distinta índole ${ }^{58}$; (iii) la deferencia de los jueces hacia la Administración tiende a ser mayor cuanto mayor es la carga de trabajo de éstos, pues entonces tienen menos tiempo para estudiar cada uno de los casos sometidos a su juicio y, por lo tanto, la referida brecha cognoscitiva es más profunda ${ }^{59}$.

Otro factor de primer orden es el riesgo de que la autoridad administrativa aproveche su margen de apreciación para desviarse de la solución que más conviene a los intereses públicos, riesgo que a su vez dependerá de otras variables, tales como los intereses o incen-

54 Quizás como consecuencia de las abundantes críticas doctrinales. Vid., entre otros, COCA VITA, E. (1983); DESDENTADO DAROCA, E. (1997); IGARTUA SALAVERRÍA, J. (1998); LÁZARO ALBA, E. y GONZÁLEZ BOTIJA, F. (2005).

55 Vid. las SSTS de 16 de diciembre de 2014 (rec. 3157/2013), 23 de diciembre de 2014 (rec. 3462/2013) y 16 de marzo de 2016 (rec. 526/2015), así como el comentario de SÁNCHEZ MORÓN, M. (2015) a la primera de ellas.

56 Vid., entre otros, CIRIANO VELA, C.D. (2000, pp. 359 y ss.); ESTEVE PARDO, J. (2009, pp. 899 y ss.); HERNÁNDEZ, J.C. (2011, pp. 284 y ss.); RUIZ PALAZUELOS, N. (2018, pp. 212 y ss.).

57 Vid., entre otras, las SSTS de 18 de mayo de 2007 (rec. 4793/2000), 2 de junio de 2010 (rec. 1491/2007), 17 de febrero de 2016 (rec. 4128/2014) y 11 de mayo de 2016 (rec. 1493/2015).

58 En sentido similar, GARCÍA ÁLVAREZ, G. (2012, pp. 1208 y 1215).

59 Vid. COAN, A.B. (2012) y, mutatis mutandis, en relación con la revisión de resoluciones judiciales por Tribunales superiores, HUANG, B.I. (2011) y LAVIE, S. (2016). 
tivos que aquélla tenga para actuar de esta manera. Cabe estimar, por ejemplo, que la independencia y las garantías de objetividad con las que están configurados ciertos órganos administrativos reducen el peligro de que se produzcan desviaciones y, por lo tanto, justifican una mayor amplitud del referido margen. El Tribunal Supremo ha declarado a este respecto que, en efecto, ese margen resulta especialmente ancho cuando el órgano administrativo decisor goza de una singular imparcialidad ${ }^{60}$, sus miembros vienen «adornados» por las cualidades de la objetividad y la independencia $^{61}$ o son «ajenos a los intereses» afectados por la decisión ${ }^{62}$.

La legitimidad democrática también juega, en ocasiones, un papel relevante. Puede mencionarse aquí la jurisprudencia según la cual el carácter directamente representativo del Pleno del Ayuntamiento -junto con el principio de autonomía municipaljustificaría que a este órgano se le pueda reconocer un margen de maniobra en la regulación de las materias reservadas a la ley más amplio que el que cabe otorgar a los gobiernos estatal y autonómico, cuya legitimidad democrática no es directa, sino mediata $^{63}$.

Puede observarse, asimismo, que la plausibilidad sustancial de una decisión y las garantías organizativas, procedimentales o formales observadas para dictarla tienden a ser sustitutivas o intercambiables hasta cierto punto. Cuanto más sospechoso o endeble sea el contenido de una decisión, más rigurosas deberán ser esas garantías a los efectos de salvar su validez. Así lo ha visto muy bien algún autor: «la posición del Tribunal Supremo sobre el rigor exigible a la motivación puede depender de las dudas sobre la justicia material de la resolución administrativa recurrida... las sombras de duda... llevan a alzar la exigencia de motivación» ${ }^{64}$. Y así se aprecia claramente en la STS de 10 de mayo de 2016 (rec. 189/2015), relativa al nombramiento del Presidente del TSJ de Murcia por el Consejo General del Poder Judicial. Éste había escogido a un candidato que había obtenido peor puntuación que otro respecto de los méritos susceptibles de mayor objetivación, y sólo había superado a éste en el mérito cuya valoración entrañaba mayor subjetividad. Así las cosas, el Tribunal Supremo considera

60 Vid. por ejemplo, la STC 353/1993, de 29 de noviembre, en relación con los órganos administrativos encargados de calificar las pruebas de acceso a la función pública.

${ }^{61} \quad$ STS de 16 de julio de 2002 (rec. 2988/1998).

62 Vid. la STS de 9 de marzo de 1993 (rec. 7217/1990), relativa a un órgano encargado de juzgar pruebas de acceso a la función pública, y la STS de 9 de diciembre de 2004 (rec. 1073/2001), relativa al «Tribunal» Marítimo Central.

63 Vid. las fundamentales SSTC 233/1999, de 16 de diciembre, y 132/2001, de 8 de junio, así como BAÑO LEÓN, J. M. (1991, pp. 147 y ss.); DOMÉNECH PASCUAL, G. (2000); BLASCO DÍAZ, J.L. (2001, pp. 130 y ss.); GALÁN GALÁN, A. (2001, pp. 230 y ss.); VELASCO CABALLERO, F. y DÍEZ SASTRE, S. (2004); VELASCO CABALLERO, F. (2009, pp. 255 y ss.); ORTEGA BERNARDO, J. (2014, pp. 303 y ss.).

${ }_{64}$ GARCÍA ÁLVAREZ, G. (2012, p. 1202). 
que «en un supuesto como el actual en que la valoración de los elementos objetivos de la recurrente se impone tan claramente sobre los del candidato designado, se revela como exigencia insoslayable un plus de motivación... que justifique debidamente la significativa relevancia concedida al resto de los requisitos anunciados... en la convocatoria». Y ello «a fin de despejar cualquier sospecha de posible arbitrariedad o desviación de poder». De hecho, después de que el acuerdo fuera anulado por no contener ese «razonamiento especialmente cuidado», el Consejo volvió a escoger al mismo candidato, pero esta vez con una motivación que la STS de 27 de junio de 2017 (rec. 4942/2016) consideró suficiente.

De ahí también que el legislador español exija una motivación reforzada a las decisiones administrativas que «se separen del criterio seguido en actuaciones precedentes o del dictamen de órganos consultivos» [art. 35.1.c) LPAG]. La razón es que esa separación constituye un «indicio de arbitrariedad en la actuación administrativa», que debe ser contrarrestado mediante una explicación particularmente rigurosa de las razones que la justifican ${ }^{65}$.

Sirva también como ejemplo la interpretación que el Tribunal Supremo ha hecho de la redacción original del artículo 24.1.b) de la Ley del Gobierno, donde podía leerse que «a lo largo del proceso de elaboración [de los reglamentos] deberán recabarse, además de los informes, dictámenes y aprobaciones previas preceptivos, cuantos estudios y consultas se estimen convenientes para garantizar el acierto y la legalidad del texto». El Tribunal Supremo ha declarado en varias ocasiones que, en principio, estos últimos «estudios y consultas» son facultativos y, por lo tanto, su omisión no constituye una ilegalidad ${ }^{66}$. Sin embargo, en su Sentencia de 9 de febrero de 2010 (rec. 591/2008), llega a la solución contraria. Para justificarla, el Tribunal, por un lado, deja sentado que la facultad prevista en dicho artículo, si bien discrecional, «no era enteramente libre», sino sujeta al principio de interdicción de la arbitrariedad y al designio de servir con objetividad los intereses generales. Por otro, llama la atención sobre las especiales circunstancias del caso: «esos informes y estudios habían sido sugeridos por el Consejo de Estado... al cuestionarse el acierto, oportunidad y hasta la legalidad de un proyecto que incidía en una materia en la que era objetivo que había diversidad de opiniones... Se trataba, pues, de una desatención procedimental relevante que se añadía a un expediente "escueto", a lo que se añade una

65 En relación con el precedente administrativo, vid. DÍEZ SASTRE, S. (2008, pp. 65 y 268 y ss.). Esta regla no está exenta de inconvenientes. Por ejemplo, puede propiciar que el autor del precedente, consciente de que será difícil cambiarlo, le dé a éste un contenido políticamente más extremo del que hubiera tenido en ausencia de semejante regla. Vid. GIVATI, Y., STEPHENSON, M.C. (2011).

66 Vid., entre otras, las SSTS de 4 de mayo de 2010 (rec. 33/2006), 15 de julio de 2010 (rec. 25/2008), 14 de mayo de 2013 (rec. 173/2012) y 24 de septiembre de 2015 (rec. 206/2007). 
serie de dudas sobre su acierto más otras no menos relevantes sobre la ilegalidad de la iniciativa» ${ }^{67}$.

Finalmente, los Tribunales también parecen ponderar la magnitud de los costes sociales que entraña la rectificación de sus eventuales errores. Cuanto más difícil y costoso resulte corregir el error consistente en dar por válida una decisión administrativa en verdad contraria al interés público, menos deferencia suelen mostrar hacia ella. Cuanto mayores son los costes que puede ocasionar declarar equivocadamente la ilegalidad de una resolución administrativa, mayor habrá de ser el margen de discrecionalidad. Éste es, por ejemplo, uno de los factores -junto con el del riesgo de desviaciones- que explica por qué dicho margen resulta, ceteris paribus, menor en las decisiones administrativas que implican un menoscabo de los recursos naturales existentes que en aquellas otras que mantienen el statu quo ambiental ${ }^{68}$.

67 STS de 24 de septiembre de 2015 (rec. 206/2007).

68 Vid. las SSTS de 13 de junio de 2011 (rec. 4045/2009) y 30 de septiembre de 2011 (rec. 1294/2008), comentadas por LOZANO CUTANDA, B. (2012). 


\section{BIBLIOGRAFÍA}

ALEXY, R. (1994), Theorie der Grundrechte, Suhrkamp, Frankfurt a. M., 1994.

ALONSO MAS, Mª. J. (1998), La solución justa en las resoluciones administrativas, Tirant lo Blanch, Valencia.

ALONSO MAS, $\mathrm{M}^{\mathrm{a}}$.J. (2003), «La ejecución de las sentencias anulatorias de actos administrativos por falta de motivación (Comentario a la STC 83/2001, de 26 de marzo)», RAP, 160, pp. 203-234.

ARAGÓN REYES, M. (2016), Uso y abuso del decreto-ley. Una propuesta de reinterpretación constitucional, Iustel, Madrid.

ARANA GARCÍA, E. (2003), La alegación de la propia torpeza y su aplicación al Derecho administrativo, Comares, Granada.

ARANA GARCÍA, E. (2013), «Uso y abuso del decreto-ley», RAP, 191, pp. $337-365$.

ARROYO JIMÉNEZ, L. (2009), «Ponderación, proporcionalidad y Derecho administrativo», InDret, 2/2009.

BACIGALUPO, M. (1997), La discrecionalidad administrativa, Marcial Pons, Madrid.

BACIGALUPO, M. (2001), «De nuevo sobre la motivación de los nombramientos discrecionales en las carreras judicial y fiscal», La Ley, 5262.

BAÑO LEÓN, J. Mª (1991), Los límites de la potestad reglamentaria, Civitas, Madrid.

BAÑO LEÓN, J. Ma . (2011), «Reserva de Administración y Derecho Comunitario», Papeles de Derecho Europeo e Integración Regional, 7.

BAÑO LEÓN, J. Ma . (2011), «Retroacción de actuaciones: ¿denegación de justicia o garantía del justiciable?», REDA, 152, pp. 839-857.

BELTRÁN DE FELIPE, M. (1995), Discrecionalidad administrativa y Constitución, Tecnos, Madrid.

BETANCOR RODRÍGUEZ, A. (2015), «La discrecionalidad, un tema clásico sobre el poder y sobre el control del poder», en ARROYO,L., BELADIEZ, M., ORTEGA, y RODRÍGUEZ, J. Ma. (coords.), El juez del Derecho administrativo, Marcial Pons, Madrid, pp. 109-148.

BLACKSTONE, W. (1769), Commentaries on the Lawes of England in Four Books, Book the Fourth, Oxford, Clarendon Press. 
BLASCO DÍAZ, J. L. (2001), Ordenanza municipaly ley, Marcial Pons, Madrid.

BOCANEGRA SIERRA, R. y HUERGO LORA, A. (2001), «Un paso atrás en el control judicial de la discrecionalidad: su confusión con los conceptos jurídicos indeterminados y la dispensa del deber de motivar», REDA, 111, pp. 405-428.

CIRIANO VELA, C. D. (2000), Administración económica y discrecionalidad, Lex Nova, Valladolid.

COAN, A. B. (2012), «Judicial Capacity and the Substance of Constitutional Law», Tale Law Fournal, 122, pp. 422-458.

COCA VITA, E. (1983), «Legalidad constitucional, exclusión de control judicial y discrecionalidad técnica», RAP, 100-102, pp. 1039-1081.

FERRERES COMELLA, V. (1997), Justicia constitucional y democracia, CEPC, Madrid.

COOTER, R. (2006), «The Intrinsic Value of Obeying a Law: Economic Analysis of the Internal Viewpoint», Fordham Law Review, 75, pp. 1275-1286.

DE VICENTE DOMINGO, R. (2014), La inactividad administrativa prestacionaly su control judicial, Civitas, Madrid.

DESDENTADO DAROCA, E. (1997), Los problemas del control judicial de la discrecionalidad técnica (Un estudio crítico de la jurisprudencia), Givitas, Madrid.

DESDENTADO DAROCA, E. (1999), Discrecionalidad administrativa y planeamiento urbanístico, Aranzadi, Elcano.

DÍEZ SASTRE, S. (2008), El precedente administrativo, Marcial Pons, Madrid.

DOMÉNEGH PASCUAL, G. (2000), «Límites sustanciales de las remisiones al reglamento en materia tributaria», Revista General de Derecho, 670-671, pp. 91839198.

DOMÉNEGH PASGUAL, G. (2007), «Es compatible con el principio ne bis in idem reabrir un procedimiento sancionador caducado?», REDA, 136, pp. 727-755.

DOMÉNECH PASGUAL, G. (2017), «Las irregularidades no invalidantes desde una perspectiva económica», en LÓPEZ RAMÓN, F. y VILLAR ROJAS, F. (eds.), El alcance de la invalidez de la actuación administrativa. Actas del XII Congreso de la Asociación Española de Profesores de Derecho Administrativo, INAP, Madrid, pp. 151-169.

ESTEVE PARDO, J. (2009), «La revisión judicial de las decisiones de las autoridades reguladoras. Jurisprudencia del Tribunal Supremo y la Audiencia Nacional», 
en MUÑOZ MACHADO, S. y ESTEVE PARDO, J. (dirs.), Regulación Económica I. Fundamentos e instituciones de la regulación, Iustel, Madrid, pp. 881-921.

FERNÁNDEZ FARRERES, G. (1983), La subvención: concepto y régimen jurídico, IEF, Madrid.

FERNÁNDEZ RODRÍGUEZ, T. R. (2012), «Sobre los límites constitucionales del poder discrecional», RAP, 187, pp. 141-170.

FERNÁNDEZ RODRÍGUEZ, T. R. (2015), «La discrecionalidad técnica: un viejo fantasma que se desvanece», RAP, 196, pp. 211-227.

FISMAN, R. Y MIGUEL, E. (2007), «Corruption, Norms, and Legal Enforcement: Diplomatic Parking Tickets», Fournal of Political Economy, 115:6, pp. 1020-1048.

FRIEDMAN, L. (2016), Impact: How Law Affects Behavior, Harvard University Press, Cambridge.

GARCÍA ÁLVAREZ, G. (2012), «El declive de la inmunidad judicial de las decisiones de los tribunales de oposiciones (análisis de la evolución de la jurisprudencia del Tribunal Supremo sobre "discrecionalidad técnica")», en GARCíA DE ENTERRÍA, E. y ALONSO GARCÍA, R. (eds.), Administración y fusticia: un análisis jurisprudencial. Liber amicorum Tomás-Ramón Fernández, vol. 1, pp. 1193-1221.

GALÁN GALÁN, A. (2001), La potestad normativa autónoma municipal, Atelier, Barcelona.

GALBIATI, R. Y VERTOVA, P. (2014), «How laws affect behavior: Obligations, incentives and cooperative behavior», International Review of Law and Economics, 38, pp. 48-57.

GARCÍA DE ENTERRÍA, E. (1991), «La lucha contra las inmunidades del poder en el Derecho administrativo (poderes discrecionales, poderes de gobierno, poderes normativos)», Revista de Administración Pública, 38, 1962, pp. 159-208.

GARCÍA DE ENTERRÍA, E. (2009), Democracia, jueces y control de la Administración, Civitas, Cizur Menor.

GARCÍA DE ENTERRÍA, E. y FERNÁNDEZ RODRÍGUEZ, T. R. (2017), Curso de Derecho administrativo, Civitas, Madrid, t. I.

GARCÍA LUENGO, J. (2016), Las infracciones formales como causa de invalidez del acto administrativo, Iustel, Madrid.

Givati, Y. (2009), «Strategic Statutory Interpretation by Administrative Agencies», American Law and Economics Review, 12:1, pp. 95-115. 
GIVATI, Y. Y STEPHENSON M. C. (2011), «Judicial Deference to Inconsistent Agency Statutory Interpretations», Fournal of Legal Studies, 40, pp. 85-113.

HERNÁNDEZ, J. C. (2011), El régimen jurídico-administrativo de las concentraciones de empresas en el derecho comunitario. Test sustantivo y control judicial, Aranzadi, Cizur Menor.

HICKS, J. (1939), «THE FOUNDATIONS OF WELFARE EGONOMICS», Economic Fournal, 49:196, pp. 696-712.

HUANG, B. I. (2011), «Lightened Scrutiny», Harvard Law Review, 124, pp. 1109-1151.

HUERGO LORA, A. (2000), Las pretensiones de condena en el contencioso-administrativo, Aranzadi, Cizur Menor.

HUERGO LORA, A. (2001), «La permanencia de un viejo problema: la reiteración de los actos administrativos anulados como forma de incumplimiento indirecto de las sentencias, con especial referencia a los efectos de los recursos de casación en interés de Ley», RAP, 156, pp. 283-306.

IGARTUA SALAVERRÍA, J. (1998), Discrecionalidad técnica, motivación y control jurisdiccional, Civitas, Madrid.

KALDOR, N. (1939), «Welfare Propositions of Economics and Interpersonal Comparisons of Utility», Economic Fournal, 49:195, pp. 549-552.

KELSEN, H. (1995), Teoría pura del Derecho, trad. R. Vernengo, Porrúa, México.

LAGUNA DE PAZ, J. C. (2017), «El control judicial de la discrecionalidad administrativa», REDA, 186, pp. 83-108.

LAVIE, S. (2016), «Appellate Courts and Caseload Pressure», Stanford Law and Policy Review, 27, pp. 57-99.

LÁZARO ALBA, E. y GONZÁLEZ BOTIJA, F. (2005), «A vueltas con la discrecionalidad técnica en oposiciones y concursos: jurisprudencia reciente y reflexiones críticas», REDA, 1127, pp. 519-554.

LOPERA MESA, G. P. (2004), «Los derechos humanos como mandatos de optimización», Doxa, 27, pp. 211-246.

LOZANO GUTANDA, B. (2012), «Principio de standstill versus discrecionalidad administrativa. Sentencia del Tribunal Supremo de 12 de junio de 2011», en GARGíA DE ENTERRÍA, E. y ALONSO GARGÍA, R. (eds.), Administración y Justicia: un análisis jurisprudencial. Liber amicorum Tomás-Ramón Fernández, vol. 1, pp. 1545-1573. 
LOZANO SERRANO, G. (2013), «La reiteración de actos tributarios anulados desde el principio de congruencia procesal», Tribuna Fiscal, 268, pp. 19-31.

MARINA JALVO, B. (2017), «La cobertura legal del reglamento de régimen disciplinario de los funcionarios de la Administración del Estado», REDA, 188, pp. 223-238.

MARTÍN GONZÁLEZ, M. (1967), «El grado de determinación legal de los conceptos jurídicos», RAP, 54, pp. 197-292.

MARTÍN REBOLLO, L. (2015), «Uso y abuso del Decreto-Ley (un análisis empírico)», REDA, 174, pp. 23-92.

MESTRE DELGADO, J. F. (2016), «Consideraciones sobre la denominada discrecionalidad técnica», en ARIAS, A., GARo, A., GHAVES, J. R. y FERNÁNDEZ, J.J. (eds.), Usos y abusos del Derecho universitario. Homenaje a fuan Manuel del Valle, Aranzadi, Cizur Menor, pp. 119-122.

MOZO SEOANE, A. (2018), La atribución legal de discrecionalidad. En torno a la discrecionalidad valorativa, Reus, Madrid.

MUÑOZ MACHADO, S. (2015), Tratado de Derecho administrativo y Derecho público general, BOE, Madrid, t. III.

NICKERSON, R. S. (1999), «Confirmation Bias: A Ubiquitous Phenomenon in Many Guises», Review of General Psychology, 2:2, pp. 175-220.

ORTEGA BERNARDO, J. (2014), Derechos fundamentales y ordenanzas locales, Marcial Pons, Madrid.

PAREJO ALFONSO, L. (1993), Administrar y juzgar: dos funciones constitucionales distintas y complementarias, Tecnos, Madrid.

PÉREZ OLEA, M. (1972), «La discrecionalidad administrativa y su fiscalización judicial», Revista de Estudios de la Vida Local, 173, pp. 41-70.

PNG, I. P. L. (1986), «Optimal subsidies and damages in the presence of judicial error», International Review of Law and Economics, 6:1, pp. 101-105.

POLINSKY, A. M. Y SHAVELL, S. (2000), «The Economic Theory of Public Enforcement of Law», Fournal of Economic Literature, 38:1, pp. 45-76.

PONCE SOLÉ, J. (2016), «La discrecionalidad no puede ser arbitrariedad y debe ser buena administración», REDA, 175, pp. 57-84. 
REBOLLO PUIG, M. (2002), «Nemo auditur propriam turpitudinem allegans en la jurisprudencia contencioso-administrativa», Documentación Administrativa, 263-264, pp. 185-221.

RIVERO YSERN, E. y RIVERO ORTEGA, R. (2012), «¿Acaso existe la discrecionalidad técnica? A propósito de la Sentencia del Tribunal Supremo de 19 de julio de 2010», en GARCÍA DE ENTERRÍA, E. y ALONSO GARCÍA, R. (eds.), Administración y Fusticia: un análisis jurisprudencial. Liber amicorum Tomás-Ramón Fernández, vol. 1, pp. 2063-2078.

RODRÍGUEZ DE SANTIAGO, J. Mª (2016), Metodología del Derecho administrativo. Reglas de racionalidad para la adopción y el control de la decisión administrativa, Marcial Pons, Madrid.

RUIZ PALAZUELOS, N. (2018), El control jurisdiccional de la discrecionalidad de los organismos reguladores. Un análisis de casos en los ámbitos de la energía y las telecomunicaciones, Aranzadi, Cizur Menor.

SAINZ MORENO, F. (1976), Conceptos jurídicos, interpretación y discrecionalidad administrativa, Civitas, Madrid.

SAMUELSON, W. y ZEGKHAUSER, R. (1988), «Status Quo Bias in Decision Making», Fournal of Risk and Uncertainty, 1:7, 1988, pp. 7-59.

SÁNCHEZ MORÓN (1994), Discrecionalidad administrativa y control judicial, Tecnos, Madrid.

SANTAMARÍA PASTOR, J. A. (2014), «Muerte y transfiguración de la desviación de poder: sobre las sentencias anulatorias de planes urbanísticos» RAP, 195, pp. 197-2015.

SESMA SÁNCHEZ, B. (2017), La nulidad de las liquidaciones tributarias, Aranzadi, Cizur Menor.

SHAVELL, S. (2012), «When Is Compliance with the Law Socially Desirable?», Journal of Legal Studies, 41, pp. 1-36.

STEPHENSON, M. G. (2006), «The Strategic Substitution Effect: Textual Plausibility, Procedural Formality and Judicial Review of Agency Statutory Interpretations», Harvard Law Review, 119, pp. 1035-1070.

STERN, S. (2002), «Cognitive Consistency: Theory Maintenance and Administrative Rulemaking", University of Pittsburgh Law Review, 63, pp. 589-644. 
TARDÍO PATO, J. A. (2018), «La problemática actual de la potestad disciplinaria sobre el alumnado de las Universidades públicas», en Actas del XIII Congreso de la Asociación Española de Profesores de Derecho Administrativo, Salamanca.

TYLER, T. R. (2006), Why People Obey the Law, Princeton University Press, Princeton.

VELASCO CABAlLERO, F. (2009), Derecho local. Sistema de fuentes, Marcial Pons, Madrid.

VELASCO CABALlERO, F. y Díez Sastre, S. (2004), «Ordenanzas municipales y reserva de ley sancionadora», Cuadernos de Derecho Local, 5, pp. 50-62.

VERMEULE, A. (2016), Law's Abnegation, Harvard University Press, Cambridge.

VIVER PI-SUNYER, G. (2013), «Los efectos vinculantes de las sentencias del Tribunal Constitucional sobre el legislador: ¿puede éste reiterar preceptos legales que previamente han sido declarados inconstitucionales», REDC, 97, pp. 13-44.

VOLOKH, A. (1997), "n Guilty Men”, University of Pennsylvania Law Review, 146, pp. 173-216. 